\title{
Antimicrobial Potentials of Phyto-synthesized Silver Nanoparticles from Laurus nobilis L.
}

\author{
Melisa Ayışığı, Tansel Yalçın, Lale Yıldız Aktaş* \\ Ege University, Faculty of Sciences, Department of Biology, Bornova, Izmir, Turkey \\ *lale.yildiz@ege.edu.tr
}

Received: 25 June 2019

Accepted: 16 September 2019

DOI: $10.18466 /$ cbayarfbe.582161

\begin{abstract}
Silver nanoparticles (AgNPs) are popular consumer product additives due to their well-known antimicrobial properties. Nowadays, their usage has increased after the emergence of green synthesis method with less toxicity than conventional methods. In this study, we aimed to reveal the antimicrobial potential of phytosynthesized AgNP by Laurus nobilis L. extracts against different Gram-positive, Gram-negative bacteria as well as Candida albicans ATCC 10231. Phyto-synthesized AgNPs were characterized by scanning electron microscopy, zeta size-potential analysis, UV-Visible spectroscopy and FT-IR analysis. The results showed that the size of AgNP was $50 \mathrm{~nm}$ and coated by phyto-constituents such as phenolic compounds according to FT-IR results. The antimicrobial activity of AgNP was determined by MIC and MBC tests. The results pointed that green synthesized AgNPs are effective against various microorganisms.
\end{abstract}

Keywords: Phyto-synthesis, silver nanoparticles, antimicrobial potential, Laurus nobilis, green synthesis.

\section{Introduction}

Nanoparticles are the materials that their sizes change between 1-100 $\mathrm{nm}$ in one dimension [1]. Nanoparticles drew attention because of their high surface to volume ratio and small size. They have altered physical and chemical properties (such as mechanical properties, catalytic activity, electrical conductivity, etc.) compared to bulk form [2]. In the view of their unique features, nanoparticles (NPs) have wide range of applications in areas like environmental health, cosmetics and health care, food and feed, drug-gene delivery, mechanics, biomedical sciences, chemical industries, optics, energy science, light emitters and nonlinear optical devices, photo-electrochemical applications electronics, space industries, optoelectronics, catalysis, single electron transistors $[3,4]$. Thus, there has been an increased demand for the nanoparticles [5]. Metallic nanoparticles are synthesized by various physical and chemical methods like vapor deposition, electrochemical synthesis, ultra-sonication, microwave-assisted synthesis [6]. The chemicals used for these synthesis methods were reported as toxic, expensive and non-eco-friendly [7].

To feed the demand of less harmful and cost-effective nanoparticle production, the biological synthesis approach from different natural sources like bacteria, fungi, plants has been suggested [8]. The studies approved that many enzymes, phenols, vitamins, hydroxyl and carboxyl groups from organic compounds can be used for green synthesis of nanoparticles instead of chemical stabilizing and capping agents [4, 9]. Especially, plants have emerged as a predominant source for the nanoparticle synthesis due to their low cost and straightforward processing potentials. Nowadays, green synthesized nanoparticles have drawn a great interest as a result of their prospective applications on disease management in medicine and agriculture [10]. Starting from 20th century, commercial medicinal products of silver colloids, such as Collargol, Argyrol, and Protargol are on sale and have been sold in markets, pharmacies and also used to treat diseases like syphilis and other bacterial infections [11]. This study aimed to evaluate the effect of phyto-synthesized silver nanoparticles (AgNPs) by for the first time using laurel (Laurus nobilis L.) extracts on the control of different pathogens.

\section{Materials and Methods}

\subsection{Nanoparticle Synthesis and Characterizations}

\subsubsection{Plant Extraction}

Laurus nobilis L. leaves (10 g) were powdered and extraction was carried out in $60^{\circ} \mathrm{C}$ for $15 \mathrm{~min}$., the extract was filtered. After filtration the extract was centrifuged for 15 minutes and the supernatant was used for the nanoparticle synthesis.

\subsubsection{Silver Nanoparticle Synthesis}

$1 \mathrm{mM}$ silver nitrate $\left(\mathrm{AgNO}_{3}\right)$ solution was mixed with leaf extract by constantly stirring at $90^{\circ} \mathrm{C}$. Reaction was stopped after 2 hours. The synthesized nanoparticles 
were then centrifuged, washed 3 times and left to dry in the oven overnight at $45^{\circ} \mathrm{C}$.

\subsubsection{Nanoparticle Characterizations}

The green synthesized nanoparticles were identified by various physicochemical characterization techniques. UV-Visible spectroscopy (Thermoscientific, UK) was used to detect the localized surface plasmon resonance peak (SPR) and formation of silver nanoparticles. The morphology and size of the prepared nanoparticles were determined by scanning electron microscopy. The surface potential and size of the nanoparticles were determined by zeta sizer-potential analysis (Malvern, UK). Organic material identification was performed by Fourier transform infrared spectroscopy (FT-IR) (Shimadzu, Japan).

\subsection{Antimicrobial Activity Tests}

\subsubsection{Minimum Inhibition Concentration (MIC)}

The minimal inhibitory concentrations of AgNP were determined by micro-dilutions method against several Gram-positive, Gram-negative bacteria as well as one yeast strain (Candida albicans ATCC 10239). Grampositive bacterial strains included (Listeria monocytogenes ATCC 19115, Staphylococcus aureus ATCC 25923 and Staphylococcus epidermidis ATCC 12228). On the other hand, Gram-negative bacterial strains included (Escherichia coli ATCC 29998, Pseudomonas aeruginosa ATCC 27853 and Salmonella typhimurium CCM 5445). The microorganisms tested in this study were provided by Ege University, Faculty of Science, Department of Basic and Industrial Microbiology (Izmir, Turkey).

The test microorganisms were grown in Mueller Hinton Broth till they reached exponential phase after $5 \mathrm{~h}$. After which the growth was adjusted to $0.5 \mathrm{McFarland}$ turbidity standard $\left(\mathrm{OD}_{600}=1.0\right)$, which corresponds to $1.5 \times 10^{6}$ colony-forming units $(\mathrm{cfu} / \mathrm{ml})$. 96-well microtiter plates containing $80 \mu \mathrm{l}$ of serially diluted AgNPs (3.9-500 mg/mL) were inoculated with $20 \mu \mathrm{l}$ of the standardized bacterial culture. The plates were checked for turbidity after incubation at $37^{\circ} \mathrm{C}$ for $24 \mathrm{hrs}$. MIC was defined as the lowest concentration of AgNP required to inhibit microbial growth. MIC was determined according to CLSI standards [12].

\subsubsection{Minimum Bactericidal Concentration (MBC)}

Minimum bactericidal concentrations (MBC) of silver nanoparticles were evaluated by sub-culturing about 5-10 $\mu \mathrm{L}$ of wells with concentration equal MIC on Mueller Hinton agar plate for microorganisms. MBC was determined as the minimal concentration that prevented growth.

\section{Results and Discussion}

\subsection{Nanoparticle Characterization}

Localized surface plasmon resonance peak (LSPR) is an indicator for the formation of metal nanoparticles and it consists characteristic patterns for each metal nanoparticles [11]. The silver nanoparticles' LSPR was determined by UV/Visible spectroscopy and results showed that the highest peak was $435 \mathrm{~nm}$ indicating the formation of AgNPs (Fig.1a). This result is consistent with the data reporting the peak between $350-500 \mathrm{~nm}$ as an indication for silver nanoparticle formation $[11,13,14]$. In the previous studies it has been mentioned that the shape of the particles is spherical at 410-500 nm SPR peak range [13] which collaborates with our UV/Vis Spectroscopy and SEM results (Fig. 1c). SEM-EDS analysis showed that nanoparticle size is $50 \mathrm{~nm}$ average, spherical in shape and silver content as $94 \%$ (Fig. 1d). The dispersion and stability of metal nanoparticles in a solution is verified by the zeta potential method. The overall charge in a solution of the sample is the metal nanoparticles' zeta potential [14]. The green synthesized AgNP was negatively charged (zeta value $=-30 \mathrm{mV}$ ) and the size was equal to $95 \mathrm{~nm}$. Hydrodynamic radii of the particles are measured the zeta sizer which includes not just the particle itself, but the ions and layers of the solvent in the solution [15]. The method is susceptible to dispersion/aggregation behavior of the particles [16]. This proved to be difficult to determine with dried solutions from microscopic data like SEM and causes the difference between SEM and zeta size results for nanoparticle size. Previous studies have reported that electrostatic repulsions of negatively charged particles confer the suspension stability [7]. The aqueous extract of Laurus nobilis leaves showed major bands at wave number 3300, 2160 and $650 \mathrm{~cm}^{-1}$ in that corresponding silver nanoparticles which showed some degree shift (Fig. 1b). These peaks may be associated with $-\mathrm{OH}$ stretching vibration of phenolic compounds, $\mathrm{C}=\mathrm{C}=\mathrm{C}$ and $\mathrm{C}-\mathrm{Br}$ stretching in polyphenolic compounds respectively [10]. The observed peaks in green synthesized AgNP shows $\mathrm{C}-\mathrm{Br}$ stretching at 600 comes from laurel extract while $\mathrm{C}=\mathrm{C}$ bending at 665 and $790 \mathrm{~cm}^{-1}$ indicate alkene compounds. A peak at $3271 \mathrm{~cm}^{-1}$ also shows the shift compared to the laurel extract (Fig. 1b). According to these results AgNPs are capped with phyto-constituents according to FT-IR results.

\subsection{Antimicrobial Activities of Green Synthesized AgNP}

Antimicrobial activity of green synthesized AgNPs against the microorganisms were assessed upon checking the wells that revealed turbidity. MIC for all of the organisms except $P$. aeruginosa were found as 250 $\mathrm{mg} / \mathrm{mL}$ and MBC as $500 \mathrm{mg} / \mathrm{mL}$. The MIC value for $P$. aeruginosa was observed as 500 and its MBC value was $1000 \mathrm{mg} / \mathrm{mL}$ which was higher than other organisms. There are numerous reports that shows the antimicrobial activities of silver nanoparticles $[10,11,17,18]$. 
Celal Bayar University Journal of Science

Volume 15, Issue 3, 2019, p 317-321
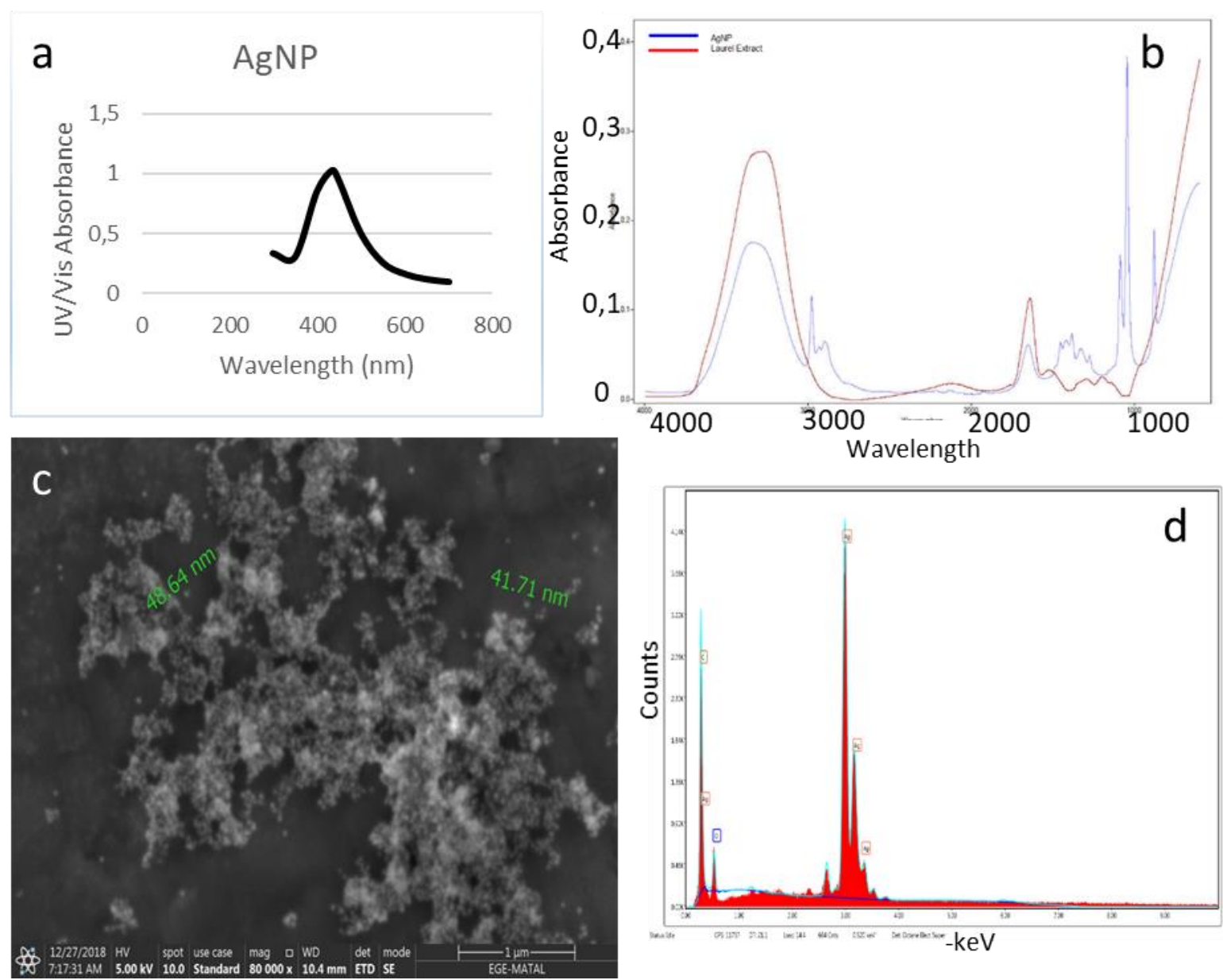

Figure 1. a) UV-Vis spectra b) FT-IR spectra c) SEM images and d) EDS results of green synthesized AgNPs

Table 1. MIC and MBC values of AgNP for different microorganisms.

\section{Bacteria}

Eshcerichia coli ATCC 29998

Staphylococcus aureus ATCC 25923

Staphylococcus epidermidis ATCC 12228

Salmonella typhimurium CCM 5445

Listeria monocytogenes ATCC 19115

Pseudomonas aeruginosa ATCC 27853

Candida albicans ATCC 10239
$\mathrm{MIC}(\mathrm{mg} / \mathrm{mL})$

250

250

250

250

250

500

250
MBC (mg/mL)

500

500

500

500

500

1000

500 
Rolim et al. [19] found that MIC and MBC values of Salmonella enterica were 7 and $15 \mu \mathrm{g} / \mathrm{mL}$ green synthesized AgNP from green tea extract, respectively. In contrast, they mentioned Klebsiella pneumoniae had the $250-500 \mu \mathrm{g} / \mathrm{mL}$ MIC and MBC values [19]. In the study of Siddiqui et al., it was reported that the \% growth of Bacillus subtilis and Bacillus cereus were totally suspended at concentration $200 \mu \mathrm{L} / 2 \mathrm{~mL}$ (or 0.1 $\mathrm{mL} / \mathrm{mL}$ ), and for Escherichia coli and Staphylococcus aureus were determined as $300 \mu \mathrm{L} / 2 \mathrm{~mL}$ (i.e., 0.15 $\mathrm{mL} / \mathrm{mL}$ ). Moreover, they reported that a good reduction in growth ratio of Bacillus subtilis was seen at $200 \mu \mathrm{L} / 2$ $\mathrm{mL}$ [20]. In another study, MIC of green synthesized AgNPs from Delphinium denudatum root extracts against the bacterial strains Staphylococcus aureus, Bacillus cereus, Escherichia coli and Pseudomonas aeruginosa were $250 \mu \mathrm{g}, 500 \mu \mathrm{g}, 500 \mu \mathrm{g}$ and $250 \mu \mathrm{g}$, respectively. The presence of plant biomolecules i.e. phenolic compounds, flavonoids and terpenoids in the extract may increase the antimicrobial activities of green synthesized silver nanoparticles [21]. The exact mechanism about the antimicrobial activity of AgNP has not been enlightened yet [20]. Previous studies suggested that AgNP can cause cellular leakage by changing membrane permeability, which consequently effects replication ability that inhibits cell growth, and eventually leads to cell death. These studies also showed that the different properties especially the size of AgNPs changed the MIC and MBC values.

\section{Conclusion}

The antimicrobial potential of green synthesized AgNP has been proved by this study and in the future the application of these nanoparticles under in vivo conditions will be possible.

\section{Author's Contributions}

The authors have no conflict of interest.

Dr. L.Y. Aktaş drafted and wrote the manuscript and PhD candidate M. Ayışı̆̆ı and Dr. T. Yalçın performed the experiment and result analysis.

\section{Ethics}

There are no ethical issues after the publication of this manuscript.

\section{References}

1. Abdelghany, T.M., Al-Rajhi, A.M.H., Al Abboud, M.A., Alawlaqi, M.M., Ganash Magdah, A., Helmy, E.A.M. and Mabrouk, A.S. 2017. Recent Advances in Green Synthesis of Silver Nanoparticles and Their Applications: About Future Directions. A Review. BioNanoScience, BioNanoScience, 5-16.

2. Iravani, S. 2011. Green Synthesis of Metal Nanoparticles Using Plants. Green Chemistry, 13, 2638-2650.

3. Dai, L.L. 2012. Advanced Core-Shell Composite Nanoparticles Through Pickering Emulsion Polymerization. The Delivery of Nanoparticles.

4. Korbekandi, H., Iravani, S. and Abbasi, S. 2009. Production of Nanoparticles Using Organisms Production of Nanoparticles Using Organisms. Critical Reviews in Biotechnology, 29, 279-306.
5. Park, Y., Hong, Y.N., Weyers, A., Kim, Y.S. and Linhardt, R.J. 2011. Polysaccharides and Phytochemicals: A Natural Reservoir for the Green Synthesis of Gold and Silver Nanoparticles. IET Nanobiotechnology, 5, 69.

6. Muthu, K. and Priya, S. 2017. Green Synthesis, Characterization and Catalytic Activity of Silver Nanoparticles Using Cassia Auriculata Flower Extract Separated Fraction. Spectrochimica Acta - Part A: Molecular and Biomolecular Spectroscopy, Elsevier B.V., 179, 66-72.

7. Chowdhury, N.R., MacGregor-Ramiasa, M., Zilm, P., Majewski, P. and Vasilev, K. 2016. 'Chocolate' Silver Nanoparticles: Synthesis, Antibacterial Activity and Cytotoxicity. Journal of Colloid and Interface Science, Elsevier Inc., 482, 151-158.

8. Vijayaraghavan, K. and Ashokkumar, T. 2017. Plant-Mediated Biosynthesis of Metallic Nanoparticles: A Review of Literature, Factors Affecting Synthesis, Characterization Techniques and Applications. Journal of Environmental Chemical Engineering, Elsevier, 5, 4866-4883.

9. Singh, P., Kim, Y.J. and Yang, D.C. 2016. A Strategic Approach for Rapid Synthesis of Gold and Silver Nanoparticles by Panax Ginseng Leaves. Artificial Cells, Nanomedicine and Biotechnology, 44, 1949-1957.

10. Vijayakumar, S., Vaseeharan, B., Malaikozhundan, B. and Shobiya, M. 2016. Laurus Nobilis Leaf Extract Mediated Green Synthesis of $\mathrm{ZnO}$ Nanoparticles: Characterization and Biomedical Applications. Biomedicine and Pharmacotherapy, Elsevier Masson SAS, 84, 1213-1222.

11. Ahmad, A., Wei, Y., Syed, F., Tahir, K., Rehman, A.U., Khan, A., Ullah, S. and Yuan, Q. 2017. The Effects of Bacteria-Nanoparticles Interface on the Antibacterial Activity of Green Synthesized Silver Nanoparticles. Microbial Pathogenesis, Elsevier Ltd, 102, 133142.

12. Clinical and Laboratory Standards Institute (CLSI). 2012. Methods for Dilution Antimicrobial Susceptibility Tests for Bacteria That Grow Aerobically; Approved Standard - Ninth Edition. Methods for Dilution Antimicrobial Susceptibility Tests for Bacteria That Grow Aerobically; Approved Standar- Ninth Edition.

13. Molecular, E.K. and Engineering, G. 2014. Green Synthesis of Silver Nanoparticles Using Oak Leaf and Fruit Extracts (Quercus) and Its Antibacterial Activity against Plant Pathogenic Bacteria. International Journal of Biosciences (IJB), 97-103.

14. Siddiqui, M.N., Redhwi, H.H., Achilias, D.S., Kosmidou, E., Vakalopoulou, E. and Ioannidou, M.D. 2018. Green Synthesis of Silver Nanoparticles and Study of Their Antimicrobial Properties. Journal of Polymers and the Environment, Springer US, 26, 423 433.

15. Costa, D., Valente, A.J.M., Queiroz, J.A. and Sousa, Â. 2018. Finding the Ideal Polyethylenimine-Plasmid DNA System for CoDelivery of Payloads in Cancer Therapy. Colloids and Surfaces B: Biointerfaces, Elsevier, 170, 627-636.

16. Eaton, P., Quaresma, P., Soares, C., Neves, C., de Almeida, M.P., Pereira, E. and West, P. 2017. A Direct Comparison of Experimental Methods to Measure Dimensions of Synthetic Nanoparticles. Ultramicroscopy, Elsevier B.V., 182, 179-190.

17. Ali, Z.A., Yahya, R., Sekaran, S.D. and Puteh, R. 2016. Green Synthesis of Silver Nanoparticles Using Apple Extract and Its Antibacterial Properties. 2016.

18. Ajitha, B., Reddy, Y.A.K., Jeon, H.J. and Ahn, C.W. 2018. Synthesis of Silver Nanoparticles in an Eco-Friendly Way Using Phyllanthus Amarus Leaf Extract: Antimicrobial and Catalytic Activity. Advanced Powder Technology, Society of Powder 
Celal Bayar University Journal of Science

Volume 15, Issue 3, 2019, p 317-321

Doi: $10.18466 /$ cbayarfbe.582161

Technology Japan, 29, 86-93.

19. Rolim, W.R., Pelegrino, M.T., de Araújo Lima, B., Ferraz, L.S., Costa, F.N., Bernardes, J.S., Rodigues, T., Brocchi, M. and Seabra, A.B. 2019. Green Tea Extract Mediated Biogenic Synthesis of Silver Nanoparticles: Characterization, Cytotoxicity Evaluation and Antibacterial Activity. Applied Surface Science, Elsevier, 463 , 66-74.

20. Siddiqui, M.N., Redhwi, H.H., Achilias, D.S., Kosmidou, E., Vakalopoulou, E., Ioannidou, M.D., Ahmad, A., Wei, Y., Syed, F., Tahir, K., Rehman, A.U., Khan, A., Ullah, S., Yuan, Q., Molecular, E.K. and Engineering, G. 2018. Green Synthesis of Silver Nanoparticles and Study of Their Antimicrobial Properties. Journal of Polymers and the Environment, Springer US, 26, 423433 .

21. Vijayan, R., Joseph, S. and Mathew, B. 2018. Green Synthesis of Silver Nanoparticles Using Nervalia Zeylanica Leaf Extract and Evaluation of Their Antioxidant, Catalytic, and Antimicrobial Potentials. Particulate Science and Technology, Taylor \& Francis, 6351, 1-11. 